1 Fundação Oswaldo Cruz (Fiocruz), Escola Nacional de Saúde Pública Sergio Arouca (Ensp), Departamento de Direitos Humanos, Saúde e Diversidade Cultural (DIHS) - Rio de Janeiro (RJ), Brasil.

jasmin.melcher@hotmail. com

2 Fundação Oswaldo Cruz (Fiocruz), Escola Nacional de Saúde Pública Sergio Arouca (Ensp), Departamento de Direitos Humanos, Saúde e Diversidade Cultural (DIHS) - Rio de Janeiro (RJ), Brasil.

mhelen@ensp.fiocruz.br

3 Fundação Oswaldo Cruz (Fiocruz), Escola Nacional de Saúde Pública Sergio Arouca (Ensp), Departamento de Direitos Humanos, Saúde e Diversidade Cultural (DIHS) - Rio de Janeiro (RJ), Brasil.

regerthal@gmail.com

\section{Violência doméstica e trabalho: percepções de mulheres assistidas em um Centro de Atendimento à Mulher}

\author{
Domestic violence and work: perceptions of women attended at a \\ Women's Care Center
}

Jasmin Gladys Melcher Echeverria1, Maria Helena Barros de Oliveiraㄹ, Regina Maria de Carvalho Erthal 3

RESUMO O presente artigo tem como objetivo analisar as relações entre mulheres em situação de violência doméstica e o seu trabalho, a partir das percepções de mulheres agredidas por seus companheiros ou ex-parceiros atendidas em um Centro de Atendimento à Mulher no estado do Rio de Janeiro. A metodologia seguiu uma abordagem qualitativa, por meio de levantamento bibliográfico, trabalho de campo, utilização de observação participante, levantamento documental e entrevistas individuais. Como resultado, destaca-se que a violência doméstica afeta o rendimento e rotina de trabalho dessas mulheres. Entretanto, o trabalho também é visto como uma saída da situação de violência a qual estão submetidas.

PALAVRAS-CHAVE Violência doméstica. Trabalho. Mulher. Assistência.

\begin{abstract}
The present article aims to analyze the relations between women in situations of domestic violence and their work, from the perceptions of women abused by their partners or ex-partners, attended at a Women's Care Center, in the state of Rio de Janeiro. The methodology followed a qualitative approach, through bibliographical survey, field work, utilization of participant observation, documental survey, and individual interviews. As a result, it is emphasized that domestic violence affects the yield and work routine of those women. However, work is also seen as a way out of the situation of violence to which they are subjected.
\end{abstract}

KEYWORDS Domestic violence. Work. Woman. Assistance. 


\section{Introdução}

A violência contra a mulher é um evento alarmante em todo o mundo. Encontra-se presente em praticamente todos os países, independentemente de suas culturas, etnias e costumes. No Brasil não é diferente: a violência contra a mulher é uma realidade na população em geral. Pesquisa de opinião, realizada pelo Data Popular e Instituto Patrícia Galvão no início de 2013, revela que a agressão contra mulheres é percebida como um dos crimes mais recorrentes no País. Além disso, essa mesma pesquisa mostra que $70 \%$ dos que foram entrevistados acham que as mulheres sofrem mais violência em ambiente doméstico, sendo a maioria das agressões praticadas pelos companheiros. A própria Lei Maria da Penha (BRASIL, 2006) considera a violência doméstica e familiar como algo recorrente no Brasil. É considerada um problema de saúde pública e uma violação dos direitos humanos. Segundo Minayo, Gomes e Silva (2005), é estimado que esse problema cause mais mortes do que certas doenças como o câncer ou a malária e do que situações como guerras ou acidentes de trânsito.

De acordo com a Declaração sobre a Eliminação da Violência contra as Mulheres, proposta pela Assembleia Geral das Nações Unidas sobre Direitos Humanos, realizada em Viena em 1993 (ONU, 1993), a violência contra a mulher é uma manifestação das relações de poder historicamente desiguais entre homens e mulheres, o que acabou conduzindo à discriminação e à dominação das mulheres pelos homens.

A construção do conceito de violência contra a mulher poderá ser mais bem compreendida a partir de uma perspectiva de gênero, que, como aponta Dantas-Berger e Giffin (2005), analisa como as relações sociais de sexo se estabelecem e se constroem ao longo do tempo na sociedade. Historicamente, nota-se a existência de uma polaridade entre o feminino e o masculino. De acordo com Welzer-Lang (2001) e Carrara
(2009), a justificativa para tal diferença era primeiramente a biológica, em que o organismo do homem, principalmente seu órgão reprodutivo, é distinto do da mulher.

Segundo Carrara (2009), além do órgão reprodutivo, muitos médicos e cientistas afirmavam que o cérebro feminino era menor do que o masculino. Essa diferença biológica justificaria os papéis que cada sexo deveria desempenhar na sociedade. Logo, a diferença entre os gêneros masculino e feminino estava vinculada ao sexo e era tratada como algo natural devido, principalmente, a diversas 'comprovações biológicas'.

Com essa naturalização do gênero, vieram outras justificativas para legitimar a hegemonia ou dominação masculina. A sociedade era organizada de forma que o sexo definia o gênero, e somente dois eram aceitáveis, o gênero feminino e o masculino, em que este último se apresentava como dominante. Assim como tinham as justificativas para diferenciar feminino e masculino, haviam justificativas para alegar que o homem era superior à mulher.

Eram várias as características e binômios para distinguir feminino e masculino, como: o homem é mais resistente fisicamente do que a mulher e, por isso, é mais forte; o homem é ativo, e a mulher, passiva; a mulher, que por natureza gera filhos, está mais ligada à emoção e à subjetividade, enquanto o homem está vinculado à razão e à objetividade, tendo que tomar decisões pelas mulheres; estas estariam mais ligadas ao ambiente doméstico/privado, enquanto o homem está ligado ao espaço público, sendo o provedor da família e tendo autonomia, e a mulher, heteronomia. A sociedade girava em torno do gênero masculino. A partir disso, pode-se perceber que essa assimetria entre feminino e masculino é fruto de uma construção social que visa manter um paradigma da diferença e da dominação masculina.

Conforme coloca Welzer-Lang (2001), existia e ainda existe uma pressão da sociedade chamada patriarcal, na qual o homem 
precisa se diferenciar do outro; do feminino. $\mathrm{O}$ autor comenta sobre toda uma postura e comportamento que o homem precisa seguir para não ser igualado ao gênero feminino. A virilidade, a coragem, o não ser afeminado, ser ativo e dominante são comportamentos que o homem 'normal' deve produzir; homens que não se enquadrassem nessa normatividade eram considerados membros do outro grupo, o grupo dos dominados, que eram pessoas consideradas fracas e que não são classificadas como homens normais, como mulheres e crianças; logo, esses homens que não seguiam a ordem normal da natureza eram estigmatizados.

Não há uma cronologia exata da origem das construções sociais que colocam a mulher em posição desigual ao homem. Essas construções acabam por ser consideradas 'naturais' e são reproduzidas, gerando ações que tentam justificar a divisão de papéis entre os gêneros e, em especial, a ocorrência da violência nesse espaço.

\section{Mulheres trabalhadoras e a divisão sexual do trabalho}

Em diversas culturas e sociedades, é observada a existência de uma divisão sexual do trabalho. Kergoat (2009) explicita esse conceito, que é associado a uma forma de divisão do trabalho derivado das relações sociais de sexo, em que cada sociedade vive essas relações de forma singular. Esse conceito tem como principais atributos a vinculação prioritária dos homens à esfera produtiva e das mulheres à esfera reprodutiva, dando aos homens funções de maior valor social. Seus princípios são colocados pela autora como dois: o da separação entre o que é trabalho para ser feito por homens e por mulheres; e o da hierarquização, em que o trabalho realizado por um homem tem mais valor do que o realizado por uma mulher. Esses princípios podem ocorrer em uma sociedade devido à legitimação de uma ideologia naturalista, abordada anteriormente, em que, a partir do sexo biológico, são atribuídos papéis diferenciados a homens e mulheres. É importante citar que a divisão sexual do trabalho não é algo rígido e imutável, seus princípios continuam os mesmos, porém suas modalidades se transformam, e este conceito não deve ser pensado apenas em relação à divisão de tarefas, e sim muito além disso, em que envolve desigualdade e exploração entre os grupos sociais. Brito (2005) coloca que a divisão sexual do trabalho é formada por relações de poder e mostra o quanto as relações de gênero estão presentes no mundo do trabalho. Algumas tarefas eram e ainda são consideradas mais adequadas de uma mulher realizar do que um homem.

Harvey (1994) e Hirata (2002) afirmam que, com o passar do tempo, principalmente durante a segunda metade do século XX, houve uma maior inclusão das mulheres no mercado formal e informal de trabalho. Com a globalização, em que se tem a reorganização internacional do capital, que traz a flexibilização do trabalho e a precarização do emprego, com novas formas de contratação e desregulamentação, que surgiram principalmente durante a década de 1970, a vulnerabilidade e a exploração do trabalho feminino aumentaram, em que muitas ocupações de trabalhadores homens mais bem remunerados e dificilmente demitíveis foram sendo substituídos pelo trabalho feminino mal pago em tempo parcial.

\section{Os Centros de Referência de Atendi- mento à Mulher}

Embora na sociedade as relações de poder se atualizem de formas específicas nas relações entre homens e mulheres, muito foi feito para que houvesse mudanças em torno da questão feminina estabelecida. As lutas feministas são um exemplo disso: elas têm um papel fundamental na tentativa de mudança da situação da mulher no mundo e na sociedade brasileira.

Várias organizações e movimentos 
feministas eclodiram pelo mundo no século XX, e no Brasil não foi diferente. A luta por igualdade de gênero e maior visibilidade da condição feminina ganhou destaque principalmente na década de 1980, em que houve um número maior de contribuições teóricas que trataram a situação feminina em suas diversas questões, como o tema da violência, tendo também a categoria trabalho como um destaque desta pauta.

As lutas pela igualdade empreendidas pelos movimentos feministas construíram várias ações e políticas públicas em torno de questões do gênero feminino. As políticas públicas começaram a ser redefinidas em torno de temas nos quais a mulher encontra-se presente, promovendo e estimulando a criação de diversos serviços no País favoráveis à desconstrução da desigualdade de gênero. Um desses serviços foram os Centros de Referência de Atendimento à Mulher, instrumento criado visando fornecer atendimento psicológico, social e, muitas vezes, orientação jurídica para mulheres em situação de violência.

Esses e outros serviços de atendimento à mulher em situação de violência fazem parte de uma rede, na qual se relacionam de forma complementar. Uma Delegacia Especializada de Atendimento à Mulher pode, por exemplo, depois de fazer um boletim de ocorrência da agressão sofrida por uma mulher, optar por encaminhar o caso a um Centro de Referência onde, após os procedimentos adequados, poderá também ser feito o encaminhamento a uma Casa-Abrigo. A utilização desses serviços pela mulher em situação de violência pode se dar de diferentes combinações e maneiras, e tudo dependerá de cada caso e de suas particularidades. Essas formas de auxílio para o enfrentamento da violência contra a mulher têm como um dos objetivos a ampliação do acesso e descentralização de informação sobre a questão da violência contra a mulher, suas consequências, serviços e direitos que podem ser acionados e reivindicados pelas mesmas. O Estado deve garantir o cumprimento desses direitos e o acesso das mulheres a esses serviços especializados. Esses serviços, por intermédio de suas intervenções, possuem um papel fundamental para o enfrentamento da violência contra a mulher no País.

\section{Metodologia}

Para a realização deste trabalho, utilizou-se uma abordagem qualitativa que, segundo Minayo e Sanches (1993), é uma forma de investigação que valoriza a fala, que destaca as representações de grupos, com suas condições socioeconômicas, históricas e culturais singulares, abordagem que bem se adequa ao objetivo deste estudo. Flick (2009) coloca que a pesquisa qualitativa permite ter acesso a experiências, interações e documentos em seu contexto natural.

Na primeira etapa, para o desenvolvimento deste trabalho, foi realizado levantamento bibliográfico em fontes tanto nacional como estrangeira, a partir de artigos, livros e pesquisa virtual. Também se utilizou a base de dados Biblioteca Virtual em Saúde, com os seguintes descritores: violência doméstica $A N D$ trabalho $A N D$ mulher\$; violência doméstica $A N D$ gênero $A N D$ trabalho. O levantamento destacou poucos trabalhos que pudessem contribuir para o objetivo proposto, evidenciando assim a importância deste estudo.

O trabalho de campo foi realizado no Centro Especial de Orientação à Mulher Zuzu Angel (Ceom Zuzu Angel), em São Gonçalo, Rio de Janeiro, dando destaque às falas das mulheres, essenciais para o desenvolvimento deste trabalho. Foram realizadas entrevistas individuais com mulheres maiores de 18 anos atendidas nessa instituição, consideradas em situação de violência doméstica e que têm ou tiveram um trabalho remunerado durante o período de violência. Também foi feito levantamento documental das fichas de acompanhamento das mulheres 
atendidas no ano de 2014. Essas fichas foram selecionadas segundo os critérios de inclusão definidos por este estudo, e as usuárias contactadas para entrevista. O ano de 2014 foi escolhido devido ao possível acesso às usuárias que ainda frequentam a instituição. As fichas do ano de 2015 não foram selecionadas, pois, de acordo com a coordenadoria do local, haveria uma mudança no cadastramento das usuárias naquele ano, o que poderia comprometer a pesquisa devido à heterogeneidade do conteúdo das fichas.

Observar o funcionamento do Centro foi importante na aproximação e interação com as mulheres atendidas. Segundo Minayo (2014), a observação participante, que promove a integração do pesquisador no contexto observado e uma relação mais próxima com os participantes da pesquisa, possibilitou o acompanhamento do caminho percorrido pelas mulheres acolhidas desde a sua entrada nessa instituição. Essa observação se deu principalmente antes do período em que ocorreram as entrevistas. Desde setembro de 2015, o espaço permanece fechado para obras, mas seus profissionais encontram-se trabalhando juntamente com o Ceom Patrícia Acioli, no bairro de Jardim Catarina, também em São Gonçalo.

Por isso, o local onde foram realizadas as entrevistas foi o Ceom Patrícia Acioli, em uma sala da instituição, onde o profissional que está atendendo a usuária também poderia permanecer, se esta se sentisse mais à vontade com a sua presença, sem, contudo, poder interferir na entrevista. É importante colocar que, por mais que o espaço das entrevistas tenha sido nessa instituição, as entrevistadas eram usuárias do Ceom Zuzu Angel, assim como os profissionais com que a pesquisadora teve contato. As entrevistas aconteceram ao longo de 3 meses, em que foram esclarecidos e apresentados os objetivos da pesquisa e perguntado se a pessoa aceitava participar.

A pesquisa foi avaliada pelo Comitê de Ética por meio do Certificado de
Apresentação para Apreciação Ética (CAAE) $\mathrm{n}^{\mathrm{o}}$ 44038215.8.0000.5240, e aprovada com parecer de número 1.564.925.

As entrevistas foram realizadas a partir de um roteiro que, de acordo com Goode e Hatt (1968), permite uma maior flexibilidade e espaço para o aprofundamento das falas das participantes. O roteiro auxiliou na orientação e na lembrança de pontos importantes a serem questionados, durante os encontros com as entrevistadas. Nas entrevistas, a fala é aspecto importante e nela se manifesta de forma diferenciada contextos e realidades singulares das entrevistadas. Como as mulheres entrevistadas falaram de suas experiências e concepções acerca do tema, cada uma narrando de maneira distinta devido as suas singularidades, essa ferramenta mostrou-se apropriada para a pesquisa.

Os dados pessoais das usuárias (como idade, etnia, escolaridade e dados de situação econômica e trabalho remunerado) foram acessados por meio da ficha de acompanhamento do Ceom Zuzu Angel.

As entrevistas foram gravadas, mediante autorização do sujeito de pesquisa, e transcritas posteriormente. As entrevistadas podiam pedir para desligar o gravador a qualquer momento.

Neste trabalho os nomes das entrevistadas foram substituídos por: Entrevistada 1, 2, 3, 4 e 5, a fim de manter o sigilo de suas informações pessoais. A pesquisadora está representada pela letra $P$.

Para analisar os dados coletados, realizou-se leitura mais aprofundada e transversal destes, possibilitando uma comparação entre eles, separando os aspectos comuns encontrados e classificando-os por categorias, em busca, como afirma Minayo (2014), da interpretação do que foi apresentado como mais significativo e representativo pelo grupo que foi estudado.

Por fim, procurou-se compreender e interpretar o material coletado a partir da fundamentação teórica estudada. 


\section{Uma breve descrição do Ceom Zuzu Angel e das entrevistadas}

Fundado no dia 26 de agosto de 1997, sendo um órgão público municipal, o Ceom Zuzu Angel carrega esse nome em homenagem à estilista Zuleika Angel Jones, que morreu em um acidente de carro no Rio de Janeiro, na saída de um túnel, durante a ditadura militar. Localizado no bairro de Neves, no referido município, essa instituição faz parte da rede de serviços oferecidos que visam combater a violência contra as mulheres. O Ceom Zuzu Angel recebe mulheres maiores de 18 anos que sofreram ou sofrem violência doméstica, de gênero ou sexual por meio de atendimento psicológico, social e jurídico, tendo como uma das principais finalidades o rompimento com a violência. $\mathrm{O}$ conjunto de profissionais que ali trabalha é composto por uma coordenadora, uma advogada, uma psicóloga, dois assistentes sociais, três pessoas na área administrativa, um motorista e um funcionário nos serviços gerais, como limpeza.

Das 23 usuárias dentro dos critérios de inclusão desta pesquisa, foram entrevistadas 5 mulheres, entre 27 e 58 anos de idade. A idade média dessas usuárias é de 36,8 anos. Infelizmente não foi possível entrevistar as 23 usuárias, pois algumas não atenderam ao telefone, e outras desmarcaram a entrevista e não deram mais retorno, ademais do esforço para que todas fossem entrevistadas.

Entre as cinco entrevistadas, quatro possuíam filhos. Estes eram filhos de seus companheiros ou maridos que praticaram a violência. No tocante à cor/raça, três se definiram brancas, duas pardas e uma amarela. Em relação ao estado civil, três eram casadas, uma solteira e uma possuía união estável quando entraram na instituição em 2014. Atualmente, três estão separadas, uma encontra-se ainda em relacionamento com o companheiro e uma não vive mais com o parceiro, 'mas às vezes tem recaídas com ele'.

O tempo de relacionamento dessas usuárias variou: o menor tempo foi 8 anos e o maior tempo juntos foram 32 anos. Nas entrevistas, três disseram ser protestantes, uma católica e uma não possuía religião, mas acreditava em Deus. Em relação à escolaridade, uma tem nível superior completo, duas completaram o ensino médio, uma tem o segundo ciclo completo (antigo ginásio) e uma possui o segundo ciclo incompleto (antigo ginásio).

Cada entrevistada possuía, em 2014, uma ocupação profissional diferente umas das outras: A Entrevistada 1 era secretária; a Entrevistada 2 era recepcionista de um hotel; a Entrevistada 3 era segurança de uma empresa; a Entrevistada 4 era representante comercial de uma empresa e a Entrevistada 5 disse que era revendedora de pão. Atualmente, as Entrevistadas 1, 3 e 4 continuam nesses empregos, a Entrevistada 2 se aposentou e a Entrevistada 5 mudou de emprego.

Em relação à violência doméstica que sofreram, predominou a violência psicológica, com cinco relatos, a física, com três relatos, um relato de violência moral e um de violência patrimonial. Das entrevistadas, quatro apontaram sofrer violência desde o início do relacionamento. É importante lembrar que essas formas de violência podem acontecer concomitantemente.

\section{Modificação na rotina de trabalho}

Encontraram-se, na literatura, poucas contribuições teóricas para a discussão da relação entre violência doméstica e trabalho, proposta por esta pesquisa. Somente duas contribuições que foram encontradas comentam sobre possíveis consequências que a violência doméstica pode causar no trabalho das agredidas. De acordo com Swanberg, Logan e Macke (2005), a perda de produtividade, atrasos e absenteísmo são alguns dos impactos que a violência doméstica pode causar na atividade laboral dessas mulheres. Estas muitas vezes deixam até seus empregos por medo de serem perseguidas ou assassinadas. 
Nas entrevistas, foi realmente detectado que o trabalho é afetado por conta da violência que as mulheres sofrem em casa. Elas apontaram que a falta de concentração, tristeza, estresse e preocupação faziam com que o rendimento no trabalho ficasse prejudicado:

Afeta né, é muito triste né. Às vezes o trabalho acabava não rendendo né. $O$ pensamento ficava longe né... então atrapalha nessas coisas... nessas coisinhas corriqueiras né, do dia a dia e tal. Você acaba pensando né. Por mais que a gente não possa ficar levando os problemas pessoais pro trabalho, é difícil né, é difícil separar. (Entrevistada 1).

Observa-se que é difícil a separação do que essas mulheres vivenciaram com seus companheiros, do cotidiano de trabalho, pois o ser humano leva consigo todas as suas experiências, satisfações, frustrações, alegrias e tristezas, que podem ser motivadores de determinados comportamentos diante de uma situação vivida. Infere-se que é complicado para uma mulher que se encontra nessa situação trabalhar sem pensar nos seus problemas e o quanto eles podem afetar o rendimento laboral delas.

Entre as entrevistadas, também foi observado que a rotina de trabalho foi modificada: quatro das cinco entrevistadas apontaram que o marido as controlava de alguma forma enquanto estavam trabalhando.

O estresse e a tristeza mais uma vez aparecem como consequências de uma rotina que foi alterada devido ao histórico de violência doméstica que sofriam com seus parceiros. O controle que a maioria das entrevistadas apontou sofrer pelos seus companheiros aparece como uma das formas de violência doméstica relatadas, podendo indicar posse pelas suas companheiras por meio do poder que desejam exercer sobre elas. Esse controle pode ser considerado uma das formas de relação de poder no qual o homem tenta impor a sua vontade no relacionamento, considerando a mulher como uma aquisição sua, na tentativa de conservar o seu papel dominante no relacionamento.

O ciúme também foi um fator apontado como uma das causas do controle que os companheiros exerciam sobre as usuárias. A Entrevistada 4 foi a que mais apontou esse fator em sua entrevista:

E as esposas dos meus tios estavam comentando outro dia em que a gente foi em um aniversário de família e eu fui dar uma cochilada: 'gente, ele tem um ciúme doentio por você porque ele vai toda hora ver se você tá realmente dormindo, ele fica observando, ele pega o celular, toda hora ele olha teu celular...'. Então quer dizer, é uma invasão total de privacidade. (Entrevistada 4).

\section{Fatores potencializadores para o sur- gimento da violência doméstica}

Durante as entrevistas, três das cinco entrevistadas apontaram que um dos fatores que deixava seus companheiros mais agressivos era o álcool.

Ele às vezes era muito violento né, ainda mais quando bebia... ele me bateu algumas vezes, eu apanhei... e eu aguentava tudo calada, com vergonha. (Entrevistada 2).

A bebida influencia muito? (Pesquisadora).

Muito, muito. Aídepois ele diz que não lembra de nada, que não foi ele... (Entrevistada 4).

De acordo com Saffioti (1987), alguns fatores como alcoolismo e o uso de drogas podem ser considerados como tentativas de escape diante de um fracasso em atingir metas. $\mathrm{O}$ homem pode, muitas vezes, tornar-se violento com sua companheira quando se torna financeiramente dependente dela ou quando a iniciativa da parceira causa constrangimento àquele que, como 'chefe de família', 
deveria resolver os problemas da família. O fracasso, então, vem justamente da limitação em atingir essas expectativas, que se encontrariam vinculadas ao papel masculino, por meio do qual se realizam condutas consideradas 'de macho', viris. Como afirma Bourdieu (2014), o homem torna-se um ser 'castrado' exatamente por ter que atingir essas metas e inibir qualidades que possam não ser consideradas masculinas. Logo, os homens, assim como as mulheres, sofrem pela divisão de papéis que são destinados a cada um pela dominação masculina.

A reestruturação produtiva, segundo Giffin (2002), diante da reorganização do capital, juntamente com políticas neoliberais, afetou as relações de gênero que estavam estabelecidas. De acordo com Dantas-Berger e Giffin (2005), ocorreu uma transição de gênero, em que os homens, que antes eram provedores e garantiam a renda da família, precisaram se adaptar e viver o desemprego ou trabalhos com salários inadequados para manter economicamente suas famílias. As mulheres não somente ajudam na renda da casa como também se responsabilizam pela provisão da renda, mudando, assim, papéis que antes eram distribuídos diferencialmente entre homens e mulheres.

A desestruturação do provedor masculino acaba provocando a sensação de fracasso, levando muitos homens a assumirem comportamentos de violência, pânico e fuga por não terem se adaptado a essas mudanças. A atualização ideológica dos gêneros, que coloca a mulher como independente, que trabalha fora e tem seu próprio dinheiro, na verdade, acaba ocultando o que está por trás disso, que é o aprofundamento das desigualdades de gênero e classe social, com o agravamento da dupla jornada e da exploração de mulheres.

Os relatos nas entrevistas apontaram que a maioria sustentava suas casas e tomava a iniciativa para resolver os problemas, porém sentiam-se sozinhas e cansadas diante da ausência de colaboração dos companheiros, tanto em relação à ajuda financeira como na atenção aos filhos e nos afazeres de casa, podendo ser observada uma insatisfação diante das expectativas de papéis que tradicionalmente deveriam ser desempenhados pelos homens.

\section{Ajuda no trabalho}

Em relação a pedir ajuda para algum funcionário do seu trabalho sobre a violência doméstica que vivenciaram, somente a Entrevistada 3 solicitou auxílio. Esta viveu uma situação complicada no final de seu casamento. Ela é segurança de uma loja de shopping, e seu marido era vendedor dessa mesma empresa, só que em locais diferentes, mas no mesmo bairro. Ela acabou descobrindo, diante das muitas fofocas que ocorreram no seu trabalho, que seu marido estava com uma amante, também vendedora, mas de outra empresa perto da loja em que o marido trabalhava. Ela acabou se separando. Quando decidiu fazer as malas do marido para ele sair de casa, ele tentou golpeá-la. Como ela é segurança e possui técnicas de defesa, conseguiu se desvencilhar do soco. Ele saiu de casa, e, mesmo separados de corpos, a amante passou a ameaçá-la no local de trabalho. Essa entrevistada contou que foi muito afetada no trabalho, pois todos ficaram sabendo, e seu sentimento foi de vergonha e tristeza.

Ela pediu auxílio para uma colega de trabalho, que indicou o Ceom Zuzu Angel como local de acolhimento e apoio. Além de pedir ajuda a essa amiga, ela também pediu apoio da empresa diante da situação em que se encontrava. A empresa nada fez para ampará-la, nem indicou qualquer instituição na qual pudesse ter informações sobre como proceder diante do que estava acontecendo. A empresa só tentava evitar o encontro das duas transferindo a Entrevistada 3 para outras lojas e demitiu o ex-marido. Além disso, a gerência pedia para que ela tivesse uma conduta passiva, ignorando os insultos proferidos pela amante, com insinuações de que ela poderia ser demitida. 
Então hoje, até meu trabalho hoje tá ameaçado por causa disso também. Porque tipo assim empresa, ela não resolve o problema, ela se livra do problema. Então ela tem a capacidade de contratar como tem a capacidade de mandar embora. Então tipo assim, até hoje me afeta no trabalho... eu já digo até que em janeiro eu vou ser mandada embora. (Entrevistada 3).

A inércia da empresa em apoiar sua funcionária diante da situação que ela estava vivenciando só fez com que esta se sentisse mais desamparada e ameaçada em perder seu emprego. Demostra, por outro lado, o despreparo da empresa diante da violência doméstica, sendo essa situação tratada, como aponta Leal (2015), na perspectiva privada, em que somente os envolvidos devem resolver o problema, desconsiderando as experiências e consequências negativas que a violência produz.

A Lei Maria da Penha (BRASIL, 2006) permite à mulher se ausentar de seu trabalho e garante a manutenção do vínculo de trabalho em situações de violência doméstica, conforme $o$ parágrafo $2^{\circ}$ do artigo $9^{\circ}$ :

§ 20 O juiz assegurará à mulher em situação de violência doméstica e familiar, para preservar sua integridade física e psicológica:

I - acesso prioritário à remoção quando servidora pública, integrante da administração direta ou indireta;

II - manutenção do vínculo trabalhista, quando necessário o afastamento do local de trabalho, por até seis meses. (BRASIL, 2006).

As outras entrevistadas não contaram para nenhum colega de trabalho sobre o que vivenciavam no âmbito doméstico, alegando sentirem-se envergonhadas e com receio da reação das pessoas. A vergonha pode ser um dos fatores que fazem com que muitas mulheres permaneçam em um relacionamento violento, o que pode resultar em anos de sofrimento ao lado do agressor. Além disso, a falta de informação de agredidas e também de empresas em como proceder diante de uma situação de violência doméstica é ainda presente, o que faz com que esse sofrimento para a mulher só se estenda, podendo chegar a casos extremos, como a morte.

\section{Trabalho como saída para o enfrenta- mento da situação de violência}

Por mais que as entrevistadas tenham apontado que a violência doméstica afetou seus trabalhos de alguma forma, impactando principalmente na produtividade e na rotina laboral, todas disseram que percebem o seu trabalho como uma 'válvula de escape', uma fuga do que viviam no âmbito doméstico. Por meio de suas atividades no trabalho, elas tentavam se ocupar com as suas atribuições, buscando esquecer os momentos vivenciados com seus parceiros.

Na verdade tudo o que eu quero é trabalhar. Viver esse lado. Me libertar um pouquinho do que eu vivo com ele. Quando eu tô trabalhando eu ocupo a cabeça, fico um pouco longe dos problemas, por mais que ele tente me controlar né... (Entrevistada 4).

O contato com os colegas de trabalho também auxiliava a esquecer dos problemas de casa, embora a maioria das entrevistadas não tenha contado sobre a questão da violência. $\mathrm{O}$ estresse, aborrecimento e a tristeza de um relacionamento agressivo poderiam ser deixados de lado quando essas mulheres estavam em suas atividades laborais, realizando suas tarefas, conversando sobre diversos assuntos, principalmente sobre as questões do trabalho.

É importante perceber que, ao mesmo tempo que as atividades de trabalho geram estresse, preocupação e influenciam na saúde da funcionária, somados com as consequências de uma violência doméstica 
vivenciada, o trabalho também traz prazer e satisfação. Algumas entrevistadas destacaram que, no ambiente de trabalho, fora da relação de conflito doméstico, conseguiam refletir melhor sobre a situação para tentar romper com o ciclo de violência, eventualmente pedindo ajuda a alguém. O sentimento de liberdade e independência enquanto estavam no trabalho também foi apontado como uma satisfação.

\section{Pedido de ajuda institucional como estratégia diante da violência doméstica}

As entrevistadas colocaram que o Ceom Zuzu Angel auxiliou na busca de estratégias para lidar com a situação da violência doméstica e nas suas relações com o trabalho. A instituição permitiu que elas refletissem sobre seus relacionamentos, tivessem maiores informações e acesso em relação aos seus direitos, esclarecessem dúvidas e buscassem possibilidades de romper com a violência. Afirmaram que são bem atendidas na instituição e que o carinho e atenção da equipe auxiliam na tentativa de recuperação da violência, dando ânimo e vontade de viver.

Refletir sobre suas vidas, entender que não estão sozinhas e que podem romper com o ciclo de violência são pontos proposto pelo Ceom Zuzu Angel. Essas reflexões podem propiciar uma melhora nas suas vidas, inclusive em relação ao trabalho. Não abandonar o trabalho, e sim o perceber como um instrumento que pode ser uma fuga diante da situação de violência que enfrentam, propiciando um alívio no momento em que trabalham, além de trazer uma satisfação de se sentirem úteis e independentes em suas vidas, auxiliando na ruptura com a violência.

\section{Considerações finais}

A pesquisa permitiu inferir que a violência doméstica praticada pelo parceiro afeta a atividade laboral, trazendo consequências no rendimento e na rotina de trabalho, sendo difícil separar os problemas de casa das atribuições de seus empregos. $\mathrm{O}$ estresse, falta de concentração, preocupação e tristeza foram sintomas apontados pelas entrevistadas quando estavam trabalhando e vivenciando a situação da violência ocasionada pelos seus parceiros. O controle e o ciúme também foram pontos destacados pelas entrevistadas, que influenciaram nas suas rotinas de trabalho.

Por meio das entrevistas, foi possível observar também fatores considerados potencializadores para o surgimento da violência doméstica, como o uso do álcool. Saffioti (1987) aponta que o consumo abusivo de bebidas alcoólicas pode se dar diante do fracasso em cumprir expectativas que tradicionalmente deveriam ser desempenhadas pelo papel do homem, podendo ter como consequência a violência. Nota-se que por mais que já tenha ocorrido uma transição de gênero, que modifica os papéis tradicionalmente desempenhados por homens e mulheres na sociedade, essa mudança é ainda gradual e 'sofrida' devido à dominação masculina ainda presente.

Uma questão colocada pelas entrevistadas é que por mais que a violência doméstica afetasse seu trabalho, principalmente no rendimento e na rotina de trabalho, este era uma válvula de escape, uma fuga diante dos problemas que vivenciavam com seus companheiros. Ao mesmo tempo que é difícil separar os problemas de casa e do trabalho, este acaba sendo um motivador para seguir em frente com suas vidas, em que a ocupação com as atividades laborais se torna uma tentativa de esquecer as experiências vividas pelo relacionamento agressivo. Além disso, o trabalho também pode ser visto como um momento de reflexão sobre suas relações, podendo trazer autonomia e liberdade para essas mulheres, o que pode influenciar no rompimento com a violência.

Além dessas questões levantadas, nota-se 
também que a maioria das entrevistadas não pediu ajuda para algum colega de trabalho por vergonha da situação vivenciada, porém pediram ajuda a algum conhecido ou parente, em que, mediante esses intermediários, elas conheceram o Ceom Zuzu Angel. De acordo com as usuárias, essa instituição auxiliou na tentativa de rompimento com a violência, fornecendo informações sobre seus direitos, instituições que pudessem ampará-las, como a Casa-Abrigo; principalmente, elas apontaram o apoio e carinho que os profissionais do Ceom Zuzu Angel ofereciam, criando mais alternativas de romper com a violência que sofriam.

A relação violência doméstica e trabalho precisa ser mais aprofundada pelas

\section{Referências}

BOURDIEU, P. A dominação masculina. 12. ed. Rio de Janeiro: Bertrand Brasil, 2014.

BRASIL. Lei $n^{\circ} 11.340$, de 7 de agosto de 2006. Diário Oficial [da] União, Brasília, DF, 8 ago. 2006. Disponível em: <https://www.planalto.gov.br/ccivil_03/Ato20042006/2006/Lei/L11340.htm>. Acesso em: 10 jun. 2016.

BRITO, J. C. O trabalho e saúde coletiva: o ponto de vista da atividade e das relações de gênero. Ciência $\mathcal{E}$ Saúde Coletiva, Rio de Janeiro, v. 10, n. 4, p. 879-890, out./dez. 2005. Disponível em: <http://www.scielo.br/ pdf/csc/v10n4/a12v10n4.pdf>. Acesso em: 2 jul. 2016.

CARRARA, S. Masculinidades em crise. Palestra proferida no CPFL Cultura, Campinas, SP, 2009. Disponível em: <http://www.cpflcultura.com.br/ site/2009/12/04integra-masculinidades-em-crise-sergio-carrara/>. Acesso em: 14 jun. 2016. contribuições teóricas que na maioria das vezes discutem essas esferas separadamente. Perceber que esses temas estão relacionados e que a questão da violência doméstica pode afetar a atividade laboral de mulheres agredidas é um passo para novas reflexões, implicando a discussão de alternativas de apoio para o rompimento desse problema de saúde pública. É importante, diante do grave quadro de situação de violência doméstica, que seja possível estabelecer condições de não extrapolar essa violência para o mundo do trabalho e, ao contrário, garantir que o direito ao trabalho seja uma possibilidade de enfrentamento da violência doméstica.
DANTAS-BERGER, S. M.; GIFFIN, K. A violência nas relações de conjugalidade: invisibilidade e banalização da violência sexual? Cadernos de Saúde Pública, Rio de Janeiro, v. 21, n. 2, p. 417-425, mar./abr., 2005. Disponível em: <http://www.scielo.br/pdf/csp/ v2ln2/08.pdf>. Acesso em: 13 jun. 2016.

DATA POPULAR; INSTITUTO PATRÍCIA GALVÃO. Percepção da sociedade sobre violência e assassinatos de mulheres. São Paulo, 2013. Disponível em: <http://www. spm.gov.br/sobre/publicacoes/publicacoes/2013/livro_ pesquisa_violencia.pdf/view $>$. Acesso em: 22 jun. 2016.

FLICK, U. Desenho da pesquisa qualitativa. Porto Alegre: Bookman, 2009. (Coleção Pesquisa Qualitativa).

GIFFIN, K. Pobreza, desigualdade e equidade em saúde: considerações a partir de uma perspectiva de gênero transversal. Cadernos de Saúde Pública, Rio de 
Janeiro, v. 18, supl., p. 103-112, 2002. Disponível em: $<$ http://www.scielo.br/pdf/csp/v18s0/13797>. Acesso em: 11 jun. 2016.

GOMES, R.; MINAYO, M. C. S.; SILVA, C. F. R. Violência contra a mulher: uma questão transnacional e transcultural das relações de gênero. In: BRASIL. Ministério da Saúde. Secretaria de Vigilância em Saúde. Impacto da violência na saúde dos brasileiros. Brasília, DF: Ministério da Saúde, 2005. p. 118-139. Disponível em: <https://www.nescon.medicina.ufmg.br/biblioteca/imagem/0199.pdf>. Acesso em: 3 jun. 2016.

GOODE, W. J.; HATT, P. K. Métodos em pesquisa social. 5. ed. São Paulo: Companhia Editora Nacional, 1968.

HARVEY, D. Do Fordismo à Acumulação Flexível. In: Condição Pós-Moderna. São Paulo: Edições

Loyola, 1994.

HIRATA, H. Globalização e divisão sexual do trabalho. Cadernos Pagu, Campinas, n. 17-18, p.139-156, 2002.

Disponível em: <http://www.scielo.br/pdf/cpa/n17-18/ n17a06.pdf>. Acesso em: 8 jun. 2016.

KERGOAT, D. As Relações Sociais de Sexo. In: HIRATA, H. et al. (Org). Dicionário Crítico do Feminismo. São Paulo: UNESP, 2009. p. 67-75.

LEAL, S. M. C. Conflitos entre parceiros íntimos. In: FLEURY-TEIXEIRA, E.; MENEGHEL, S. N. (Org.). Dicionário Feminino da Infâmia: acolhimento e diagnóstico de mulheres em situação de violência. Rio de Janeiro: Fiocruz, 2015. p. 63-64.
MINAYO, M. C. S. O desafio do conhecimento: pesquisa qualitativa em saúde. 14. ed. São Paulo: Hucitec, 2014.

MINAYO, M. C. S.; SANCHES, O. QuantitativoQualitativo: oposição ou complementaridade. Cadernos de Saúde Pública, Rio de Janeiro, n. 9, v. 3, p. 239-262, jul./set. 1993. Disponível em: <http://www. scielo.br/scielo.php?script=sci_arttext\&pid=S0102-311X1993000300002 >. Acesso em: 10 jun. 2016.

ORGANIZAÇÕES DAS NAÇÕES UNIDAS (ONU). Declaração sobre a Eliminação da Violência contra as Mulheres. 1993. Disponível em: <http://direitoshumanos.gddc.pt/3_4/IIIPAG3_4_7.htm>. Acesso em: 8 jun. 2016.

SAFFIOTI, H. I. B. O Poder do Macho. São Paulo: Moderna, 1987.

SWANBERG, J. E.; LOGAN, T. K.; MACKE, C. Intimate partner violence, employment, and the workplace: consequences and future directions. Trauma Violence Abuse, Thousand Oaks, v. 4, n. 10, p. 286-312. Disponível em: <http://www.workplaceviolence911. com/docs/20060324-01.pdf>. Acesso em: 8 jun. 2016.

WELZER-LANG, D. A construção do masculino: dominação das mulheres e homofobia. Revista Estudos Feministas, Florianópolis, v. 9, n. 2, p. 460-482, 2001. Disponível em: <http://www.scielo.br/pdf/ref/ v9n2/8635.pdf>. Acesso em: 8 jun. 2016.

\footnotetext{
Recebido para publicação em agosto de 2016

Versão final em novembro de 2016

Conflito de interesses: inexistente

Suporte financeiro: não houve
} 